\title{
Uma memória das lutas feministas brasileiras: 1976 a 1988
}

\author{
Memories of Brazilian feminist struggles: 1976 to 1988
}

\author{
Hildete Pereira de Melo Hermes de Araujo \\ Universidade Federal Fluminense, Brasil \\ hildete43@gmail.com
}

\begin{abstract}
Resumo:
Este artigo tem como objetivo narrar a chegada das feministas das gerações dos anos 1960/70 ao espaço político brasileiro e desta forma recuperar a história dessas lutas e que culminaram com a escrita dos direitos cidadãos na Carta Constitucional do Brasil de 1988. Mas, esta narrativa foi elaborada como notas memorialistas da autora que viveu com paixão estes momentos da luta pela democracia no Brasil e seu encontro com o ideário feminista que emergia, naqueles anos, no cenário da sociedade brasileira. Assim, estas memórias foram construídas da seguinte forma: primeiro faz-se um breve histórico das lutas feministas ao longo da primeira República, para situar os leitores nos tímidos avanços conquistados pelas brasileiras ao longo daquelas décadas. Em seguida narra os tempos de mobilização, conquistas e derrotas vivenciadas pelo movimento feminista do Brasil, a partir da convocatória da ONU para a "Conferência Internacional da Mulher", em 1975 e que permitiu as ativistas feministas, em pleno regime militar, a criarem o Centro da Mulher Brasileira (CMB). Enfatiza que este intenso ativismo possibilitou que mulheres tenham tido uma participação pioneira na gestão da política pública nacional. Sem dúvida este teve seu marco mais significativo, em 1985, com criação do Conselho Nacional dos Direitos da Mulher (CNDM), órgão público responsável por esta política e pelas vitórias obtidas pelas mulheres na redação da Carta Constitucional de 1988, embora diversas derrotas tenham acontecido, como mostra estas memórias. Estas explicadas pelo forte sexismo presente tanto ontem como hoje na política brasileira.
\end{abstract}

Palavras-Chave: Feminismo, Constituição Federal 1988, Conselho Nacional dos Direitos da Mulher, Políticas Públicas, Brasil.

\begin{abstract}
:
This article aims to narrate the arrival of the feminists of the generations of the 1960s and 1970s to the Brazilian political space and thus recover the history of these struggles and culminated in the writing of citizens' rights in the Brazilian Constitutional Charter of 1988. But this narrative was written as memorialist notes by the author who lived with passion these moments of the struggle for democracy in Brazil and her encounter with the feminist ideology that emerged, in those years, in the scenario of Brazilian society. Thus, these memoirs were constructed as follows: first a brief history of the feminist struggles throughout the first Republic, to situate the readers in the timid advances conquered by the Brazilian ones during those decades. She narrates the times of mobilization, conquest and defeat experienced by the Brazilian feminist movement, following the UN's call for the "International Women's Conference" in 1975, which allowed feminist activists, under the military regime, to create the Center for Brazilian Women (CMB). Emphasizes that this intense activism enabled women to have a pioneering participation in the management of national public policy. This was undoubtedly the most significant milestone in 1985, with the creation of the National Council for Women's Rights (CNDM), the public body responsible for this policy, and the victories won by women in the drafting of the 1988 Constitutional Charter, although several defeats occurred, as these memories show. These are explained by the strong sexism present both yesterday and today in Brazilian politics.
\end{abstract}

Keywords: Feminism, Federal Constitution 1988, National Council of Women's Rights, Public Policies, Brasil.

\section{INTRODUÇÃo}

Refletir sobre os feminismos que explodiram no Brasil a partir de 1975 e tiveram um ápice na aprovação da Constituição Federal de 1988 para a vida das brasileiras significa rasgar a cortina de silêncios que envolvem a construção da cidadania das mulheres no Brasil. Em todos os aspectos relacionados à cidadania, 
as mulheres tiveram dificuldades de acesso, seja no Brasil, seja no mundo. Os direitos civis e políticos foram particularmente resistentes e fechados às mulheres. Não é à toa que a BBC Brasil (2018) publicou o resultado de uma pesquisa com os leitores da $B B C$ World History sobre as "mulheres" que tiveram o maior impacto na história do mundo e a terceira mais votada foi a sufragista Ermeline Pankhurst (1858- 1928), uma das fundadoras do movimento britânico pelo direito ao voto. Como as ações das mulheres inglesas paulatinamente espalharam-se pelo mundo, permitiram que mulheres conquistassem o direito de votar. ${ }^{1}$ Destacamos este fato porque, sem a participação efetiva das mulheres na vida política de seus países, uma cortina do silêncio encobre os demais aspectos das vidas femininas e não é por acaso as mulheres são apenas traços na história da humanidade (Perrot, 2005).

Este artigo tem como objetivo narrar a chegada das feministas das gerações dos anos 1960/70 ao espaço político brasileiro. Para isso recuperou-se a história das lutas feministas destes anos que culminaram com a escrita dos direitos cidadãos na Carta Constitucional de 1988. O texto foi redigido como notas memorialistas da autora que viveu com paixão estes momentos.Militante estudantil desde os anos 1961, na cidade de Campina Grande (Paraíba), ingressou na universidade em 1963 e, no ano seguinte, foi bruscamente constrangida pelo golpe militar de 1964 que depôs o presidente João Goulart e instaurou o regime de exceção no país. Por motivos estritamente familiares, com o diploma de economista debaixo do braço, foi em dezembro de 1966 estudar na França e lá viveu até a segunda metade de 1968. Assistiu às revoltas estudantis e operárias daquele ano e voltou ao Brasil. Logo os militares endurecem o regime com a promulgação do Ato Institucional No 5 de 13 de dezembro de 1968. Até então era uma simples militante de esquerda; as demandas feministas não tinham ainda nem aqui e nem na França ganhado as praças e as mulheres. O clima político tenso na Paraíba culminou com minha vinda com a família, marido e dois filhos para o Rio de Janeiro em janeiro de 1970.

O jovem casal, ele doutor em engenharia da computação e eu economista com dois filhos e um doutorado incluso na França, enfrentou logo o preconceito contra as mulheres ao ter rejeitada sua inscrição numa seleção promovida pela IBM do Brasil, em 1971. Simplesmente a inscrição foi negada! Intrigada ouvir de amigos engenheiros da companhia que eu era casada e mãe de dois filhos pequenos não tinha lugar na companhia. $\mathrm{E}$ que era preferível não recorrer à Justiça, porque a chance de ser reprovada na prova era enorme. Foi minha primeira pancada do patriarcalismo/machismo. Fiz um concurso e ingressei no magistério universitário, lá acabei me envolvendo com política e a repressão atuou de forma drástica. Demitida e já inserida no ambiente político carioca descobri o feminismo.

O anúncio pela Organização das Nações Unidas (ONU) do Ano Internacional da Mulher, em 1975 desencadeou as primeiras mobilizações de mulheres e estas foram mais fortes na cidade do Rio de Janeiro. Acossada pelo regime militar entrei de cabeça nas lutas feministas nacionais no ano de 1976 . Este breve relato situa minhas lembranças sobre a luta feminista nacional que, a partir do Rio de Janeiro nos anos 1975/1976, propaga -se pelo território nacional. Esta memória está construída da seguinte forma: primeiro faz- se um breve histórico destas lutas ao longo da República, para situar os leitores nos tímidos avanços conquistados pelas feministas ao longo daquelas décadas republicanas. Em sequência constrói os tempos de mobilização, conquistas e derrotas vivenciadas pelo movimento feminista no processo de redemocratização e na elaboração constitucional.

\section{UMA BREVE história SObRe a PARTICIPAÇÃo DAS MULHERES NAS LUTAS FEMINISTAS REPUBLICANAS}

No Brasil, como nos demais países, a obtenção do direito de voto foi uma luta árdua e só foi conquistado depois de 42 anos de lutas femininas em todo o território nacional. Estas foram iniciadas com os escritos de Josefina Alvares de Azevedo de 1890/1891, continuada com o registro do Partido Republicano Feminino em 1910, ${ }^{2}$ por Leolinda de Figueiredo Daltro, Gilka da Costa Machado, Maria Carlota Vaz de Albuquerque, 
Hermelinda Fonseca da Cunha e Silva e tantas outras mulheres anônimas. Depois da I Grande Guerra mulheres brancas e educadas como a bióloga Bertha Lutz, Jerônima Mesquita, Stela Durval, Ana Amélia Carneiro de Mendonça, a sindicalista negra Almerinda Gama e outras centenas de mulheres, organizadas pela Federação Brasileira pelo Progresso Feminino em praticamente todos estados brasileiros participaram ativamente da luta sufragista. A verdade foi que as mulheres lutaram, nas ruas, nos corredores do Parlamento Nacional, nos palácios e nos bastidores do poder pela conquista da cidadania (Pereira de Melo, 2016).

No entanto, na história oficial está escrito que o Presidente Getúlio Vargas, outorgou o direito de voto às mulheres pelo Decreto No 21.076 de 24 de fevereiro de 1932. Todos os atos de protestos, manifestações que as mulheres haviam feitos ao longo de todo o período da primeira República foram apagados e nenhum registro que nos tempos imperiais o direito de voto era concedido apenas aos homens. A Constituição Federal de 1934 "tropegamente" manteve o direito de voto às mulheres, na realidade este foi facultativo para elas. A exceção apenas para às pouquíssimas funcionárias públicas (Novaes Marques, 2016). Finalmente, a Constituição de 1946 concede o direito de voto as pessoas que sabemler e escrevereobrigatório para ambos os sexos. No entanto, entre os direitos civis e políticos e o acesso das mulheres na sua plenitude cívica, estas foram conquistas paulatinas no Brasil. A plenitude da cidadania feminina não foi obtida facilmente e até 1988, elas eram apenas colaboradoras do marido, competindo a eles a chefia da sociedade conjugal. Esta igualdade entre os cônjuges foi escrita no Art. 226, Inc. $5^{\circ}$ da Constituição Federal de 1988.

\section{ArRombando A PORTA do mundo Político nos anos 1970/80}

Depois das revoltas estudantis e operárias de 1968 ainda timidamente novas mulheres recém-saídas das universidades brasileiras passaram a ter contato com o pensamento feminista que emergiam no cenário dos países do norte e os escritos de acadêmicas americanas, francesas, inglesas e italianas penetraram no Brasil. $\mathrm{O}$ pensamento feminista, ou os estudos sobre a mulher possibilitaram que no ambiente sufocante da sociedade brasileira uma discussão progressista fosse travada, sem um temor explicito dos militares. Por que os direitos das mulheres que a convocatória da ONU permitia falar, trocar ideias com outras mulheres e estes debates foi agarrado com tenacidade por um grupo de mulheres cariocas e pelas demais nos outros estados.

Como tudo, em julho de 1975, um grupo de mulheres do Rio de Janeiro organizou, sob a proteção da ONU, começou um seminário sobre a situação das mulheres brasileiras na Associação Brasileira de Imprensa (ABI) no Rio de Janeiro - "O papel e o comportamento da mulher na realidade brasileira". O sucesso foi enorme e no mês seguinte foi criada no Brasil, a primeira organização feminista da segunda metade do século XX - o Centro da Mulher Brasileira do Rio de Janeiro. Logo a cidade de São Paulo criou o Centro Paulista e em cascata, em várias cidades surgiram entidades feministas (Teles, 2017).

No ano de 1976, abracei as novas lutas que clamavam pelo reconhecimento da importância das mulheres na sociedade e denunciavam sua invisibilidade econômica e social. A leitura naquele ano foi o livro " $A$ mulher na sociedade de classes: mito e realidade" de Heleieth Saffioti (1976), que abriu para mim novos horizontes políticos e de vida e a partir de então dediquei o trabalho político a estas novas ideias feministas que céleres já corriam o mundo. O Centro da Mulher Brasileira (CMB) foi a porta de entrada da atividade política feminista, agora consciente das lutas igualitárias de sexo, classe e raça.

\section{O Centro da Mulher Brasileira do Rio de Janeiro}

Meses depois de fundado o CMB já contava com uma sede no centro do Rio de Janeiro, duas salas na Avenida Franklin Rooselvelt, 39 no sétimo andar. Suas reuniões eram geralmente nos sábados à tarde, frequentado por cerca de 30 a 50 mulheres e muitas vezes havia reuniões a noite durante a semana. A maioria das mulheres era branca, com formação universitária, casadas, com filhos pequenos e iniciantes na vida profissional. As frequentadoras do CMB tinham pequenos grupos de reflexão que se reuniam nas suas 
casas para discutir o "ser mulher", ler livros, estudar o feminismo. Nas reuniões dos sábados discutíamos a conjuntura política e o que se podiam fazer para avançar com a luta feminista no país, programar atividades conjuntas, como atos políticos e discussões de políticas públicas para as mulheres.

Cheguei ao CMB em agosto de 1976. Embora a palavra de ordem fosse a horizontalidade, e negássemos a prerrogativa de cabeças pensantes, havia um grupo mais assíduo e com mais liderança formado por Jacqueline Pitanguy, Branca Moreira Alves, Leila, Comba Porto, Malu, Mariska, Elisa, Sandra, Rose Marie, Moema, Fanny, Santinha, Viviane, Heloneida, Leonor, Lidia, Carmen da Silva. Havia muitas outras que iam e viam com menos regularidade, mas eram atentas às questôes. Havia muitas sociólogas, advogadas e poucas economistas como eu. Os destaques eram as feministas anteriores a 1975, como Heloneida Studardt, Moema Toscano, Rose Marie Muraro, Fanny Tabac. Heloneida Studardt era jornalista e havia coberto a Conferência Internacional da Mulher, no México, em 1975, pela revista Manchete. Moema e a Fanny eram professoras de ciências sociais e Rose Marie Muraro era já uma influente editora brasileira. Estas mulheres foram ponta de lança para a criação do $\mathrm{CMB}$ e, inclusive, muitos anos depois, soubemos que a Rose Marie era a responsável pelo pequeno financiamento do Ministério da Educação e Cultura (MEC) que permitia pagar o aluguel daquela sala. Ironia e esperteza feminina uma alta funcionária, simpatizante do feminismo junto com Rose Marie faziam um projeto cultural que cobria o aluguel destas salas. Só a morte desta funcionária anos depois interrompeu este financiamento.

As tardes de sábado eram dedicadas às discussões sobre nossas vidas, as relações com filhos, maridos o que devia mudar nas políticas para construir a verdadeira cidadania feminina, os lemas: trabalho igual para salário igual, nosso corpo nos pertence, o privado é politico foram as consignas daqueles tempos. Os livros de Simone Beauvoir, Betty Friedan, o livro do Coletivo de Mulheres de Boston - Nossos Corpos, Nossas Vidas, as obras de Heleieth Saffiotti, e de Heloneida, como a peça teatral "O homem não entra", fize ramparte das inúmeras discussões. Logo o grupo Ceres (Branca, Jacqueline, Leila, Mariska, Sandra) publicou um livro com suas reflexões e pesquisa sobre a sexualidade feminina - Espelho de Vênus, Identidade social e sexual da mulher (1981). Por este canal, vieram ao público muitas discussões foram travadas nas tardes de sábado no Centro. As advogadas iniciaram um projeto para a redação de um novo Código Civil que atendesse a nova mulher que se gestava. As economistas, agora com a presença de outras, como Ângela Fontes e de advogadas trabalhistas, voltaram-se para as questões do mercado de trabalho. Havia uma intensa articulação com a Ordem dos Advogados do Brasil (OAB) e dela surgiu a OAB Mulher.

Nestes anos finais da década de 1970 o clima político acirrou-se com a proposta deabertura lenta e gradual do general Golbery na presidência do General Ernesto Geisel: finalmente esta propostavenceu a luta política no estamento militar e o Congresso Nacional aprovou a Lei da Anistia (Lei No 6.683 de 28/08/1979) que absolvia a todos - direita e esquerda - de todas as acusações criminais. As prisões foram abertas e xs exiladxs puderam voltar. Havia muitas mulheres no exílio e estas voltaram já abraçando a onda feminista que varria os EUA e Europa e aqui encontraram um clima efervescente.

No Rio de Janeiro o CMB recebeu as exiladas cariocas e outras que vieram morar na cidade. As reuniões dos sábados encheram-se de novas vozes e ideias e estas tardes foram plenas de debates entusiasmados. Rapidamente, os temas da descriminalização do aborto e da violência doméstica tomaram conta dos debates e o tema do aborto nos dividiu. Não que as militantes do CMB fossem contra, mas é que as feministas chegadas da França não admitiam o silêncio que envolvia o tema até então no Brasil. Explicávamos que, devido à aliança estabelecida com alguns setores religiosos, havíamos adotado uma postura de silêncio em relação à interrupção da gravidez indesejada, mas estas novas vozes aguerridas colocaram o tema na agenda e o aborto começou a ser debatido entre nós.

Quando, em janeiro de 1980, explodiu nos jornais a notícia de prisões de mulheres e de médicos com o estouro de uma clínica de aborto em Jacarepaguá. Fortalecidas pelo debate reagimos imediatamente e uma manifestação foi organizada na porta da delegacia naquela mesma semana. Um grupo de vinte a trinta 
mulheres foram ao centro do Rio de Janeiro, ao lado da Estação da Central do Brasil negociar a liberdade das mulheres. Os donos da clínica já haviam feito o pagamento da fiança e elas haviam sido liberadas para responderem ao processo em liberdade. O protesto se dirigiu para o tribunal do Júri, onde o processo tramitava. A manchete de um grande jornal brasileiro (Jornal do Brasil) no dia seguinte afirmava que pela primeira vez no Brasil tinha havido um protesto feminino contra a criminalização do aborto voluntário. Foram inúmeras entrevistas com militantes cariocas nas revistas Veja e Playboy, debate na TV Globo. Daí para frente, a agenda feminista incorporou definitivamente a luta pela descriminalização do aborto na sua pauta de lutas, sem receio do patrulhamento religioso.

A efervescência política explodia e as eleições mais amplas foram convocadas para 1982, agora com novos partidos e eleições diretas para os governos estaduais e municipais e o movimento feminista timidamente ensaiou ser ouvido pela política. Que dureza! Naquele momento nem os partidos políticos à direita e nem à esquerda acreditavam muito na nossa força e resiliência. Como as feministas eram majoritariamente do espectro de esquerda os companheiros nos aturavam, mas o poder político no interior dos partidos era exercido por eles. A concessão sempre era uma comissão feminina ou secretaria de mulheres no tecido partidário. Nada, além disso. Esta eleição foi o prenúncio de novos tempos e com o leque partidário ampliado várias feministas concorreram no Brasil para Câmara de Vereadores, Assembleias Legislativas, Congresso Nacional (Pereira de Melo, 2017).

No Rio de Janeiro, foram lançadas para a Câmara de Vereadores as candidaturas de Benedita da Silva pelo Partido dos Trabalhadores (PT), da advogada Comba Marques Porto, pelo Partido do Movimento Democrático Brasileiro (PMDB). Para Assembleia Legislativa do Rio de Janeiro as candidaturas de Heloneida Studart, pelo PMDB, e de Lúcia Arruda pelo PT. Para o Congresso Nacional, surgiram várias candidaturas federais em diversos estados. Assim, das quatro deputadas federais da legislatura 1979-1983, foram eleitas oito mulheres deputadas federais, participação ainda exígua, mas tinha dobrado. E eleitos os governadores oposicionistas Franco Montoro (PMDB) para São Paulo, Trancredo Neves (PMDB) em Minas Gerais e Leonel Brizola (PDT) no Rio de Janeiro.

As eleições de 1982 provocaram grandes discussões no seio do movimento feminista, com reuniões virando noites, debatendo-se se o movimento deveria participar de forma organizada nos governos estaduais eleitos naquele ano. Concretamente, decidiu-se que esta atuação deveria acontecer através de conselhos formados por mulheres atuantes nos movimentos de mulheres e feministas que lutavam pela construção da igualdade entre mulheres e homens, contra a violência, pela saúde, pela participação política, contra o racismo. Esta forma de atuação e participação nas políticas públicas acabou sendo rotulada de feminismo de governo. É a raiz da profusão de órgãos de mulheres no tecido político nacional desde então. ${ }^{3}$

Quais eram as políticas públicas candentes que estavam no debate político daqueles tempos? A violência contra a mulher, saúde com o nó cravado da luta pela descriminalização do aborto. Mas, era necessário um atendimento completo à saúde materna e a pressão das feministas sobre o Ministério da Saúde levou, em 1983, à criação do PAISM (Programa de Atenção à Saúde da Mulher), -luta travada por um punhado de feministas de vários estados, que finalmente tornou- se uma política pública que paulatinamente foi implementada a partir daquele ano. Mas, a luta pela descriminalização do aborto esbarrava na renhida oposição religiosa, que de forma proposital teimava e teima em não reconhecer o direito das mulheres de escolherem ou não a maternidade. Como esta fica ao sabor do acaso ou azar, já que não existe um método seguro para evitar uma gravidez indesejada. Ao longo destes anos diversos projetos foram apresentados ao Legislativo nacional por parlamentares e muitos foram assessorados pelo movimento feminista, mas continuamos derrotadas pelas forças religiosas conservadoras nacionais até os dias atuais.

Portanto, a efervescência política desses primeiros anos da década de 1980 foi marcada pela diversidade da agenda feminista, da luta contra a violência contra as mulheres a ao direto ao aborto. A pauta da violência tinha explodido depois dos assassinatos de Ângela Diniz (RJ), Maria Regina Rocha e Eliane Ballesteros (MG), e de Eliane de Gramont (SP) e, em diferentes estados, foram criados grupos de mulheres de combate 
a violência, intitulados de SOS Mulher. Esta militância originou a iniciativa pioneira de acolhimento das mulheres em situação de violência, respondida pelo governo oposicionista aos militares de São Paulo com a criação da Delegacia Especializada de Atendimento às Mulheres (DEAM), ainda em 1985. Esta iniciativa propagou-se depois por diversas unidades da Federação e seu sucesso estimulou as feministas a proporem uma ação do Estado no combate a violência contra as mulheres que culminará com a promulgação da "Lei Maria da Penha" de combate a violência contra as mulheres nos governos petistas no século XXI. A pauta identitária também foi para as ruas e o movimento lésbico fundou em São Paulo o Grupo Lésbico Feminista, tendo como ativistas Lourdinha Rodrigues, Rosely Roth, Miriam Martinho Rodrigues, pioneiras na introdução da luta homossexual no feminismo brasileiro.

\section{A redemocratizaÇão e O Processo constitucional - o CNDM}

Os anos 1983 a 1985 foram plenos de disputas políticas e a luta pela eleição direta para Presidente da República tomou conta do Brasil. As mulheres aliaram -se a esta bandeira, mas empunhavam outra relativa às pautas igualitárias, organizadas em grupos feministas espalhados nacionalmente e também nos partidos políticos tentaram abrir brechas na política nacional. No PMBD, havia o PMDB Mulher e no PT também havia um grupo forte de feministas atuantes no espaço partidário. Na sociedade, as feministas negras também se articularam em torno de intelectuais negras como Lélia Gonzalez (1935-1994) e Beatriz Nascimento (1942-1995) organizaram encontros estaduais e nacionais e formaram coletivos políticos de mulheres negras em diferentes estados. O movimento feminista nacional abriu- se em diferentes leques, brancas, negras, lésbicas, partidários, religiosos, havia feministas em praticamente todas as consignas libertárias.

Em abril de 1984, o movimento democrático brasileiro foi derrotado politicamente com a não aprovação da Emenda Dante de Oliveira, que propunha eleições diretas para a Presidência da República pelo Congresso Nacional. A eleição indireta prevaleceu para escolher o primeiro Presidente da República depois dos governos militares. O governador mineiro Trancredo Neves lançou sua candidatura para Presidente da República, venceu as resistências de alguns setores políticos e firmou -se como candidato do partido oposicionista, o PMDB. No interim destas negociações parlamentares a deputada estadual Ruth Escobar, presidente do PMDB Mulher iniciou uma articulação com o movimento feminista para negociar com o então candidato Tancredo Neves, a criação de um órgão similar aos conselhos estaduais de Minas Gerais e de São Paulo no nível nacional. Esta articulação política do PMDB Mulher foi bem- sucedida com o comprometimento de Trancredo Neves com a criação de um órgão nacional. Neves foi eleito indiretamente pelo Colégio Eleitoral em 15 de janeiro de 1985, tendo como vice-presidente o deputado José Sarney, o que sinalizou o fim da ditadura militar e o início de um novo ciclo democrático para o Brasil.

O PMDB Mulher alvoroçou -se, e preparou- se uma caravana de feministas, deputadas estaduais, vereadoras para a posse do primeiro Presidente civil depois do golpe militar de 1964. Como militante do PMDB Mulher do Rio de Janeiro fiz parte desta caravana, mas fomos surpreendidas no início da noite do dia 14 de março de 1985 com a internação no Hospital de Base de Brasília do candidato eleito Neves que depois de uma cirurgia na madrugada daquele dia não tomou posse no dia seguinte e, em consequência, viria a falecer no dia 21 de abril daquele ano. A comitiva de mulheres feministas que tinha ido para posse do presidente civil assistiu "bestificada" à posse do vice-presidente deputado Sarney como Presidente da República, no dia 15 de março de 1985. As negociações para a criação do Conselho Nacional dos Direitos da Mulher (CNDM) que tinham sido feitas com Trancredo Neves pela deputada estadual Ruth Escobar 4 foram honradas pelo novo Presidente da República e, em maio, o governo federal publicou o Decreto No 91.227 de 6/05/1985, criando uma Comissão Especial para elaborar o anteprojeto de criação do CNDM, presidida por Escobar.

Finalmente o Presidente José Sarney encaminhou ao Congresso Nacional projeto de Lei propondo a criação do Conselho Nacional dos Direitos da Mulher (CNDM). Este projeto foi aprovado como Lei $n^{\circ}$ 
7.335 (Diário Oficial da União -DOA- de 30 de agosto de 1985), vinculando o CNDM à estrutura do Ministério da Justiça, com dotação orçamentária e recursos humanos (Pereira de Melo, 2018).

As conselheiras nomeadas foram de uma maneira geral indicadas pelo PMDB Mulher e coordenadas pela deputada estadual Escobar. E o CNDM teve sua primeira composição com as seguintes mulheres: como conselheiras efetivas, Escobar (primeira Presidenta), Ana Montenegro, Benedita da Silva, Carmen Barroso, Hildete Pereira de Melo, Jacqueline Pitanguy, Lélia Gonzalez, Maria da Conceição Tavares, Maria Elvira Salles Ferreira, Marina Bandeira, Marina Colassanti, Nair Goular, Nair Guedes, Rose Marie Muraro, Ruth Cardoso, Sonia Germano, Tizuko Yamasaki e conselheiras suplentes Margarida Genevois, Maria Betânia Ávila e Maria Lucia Pisolante. Este conselho era composto por mulheres da classe média, brancas e duas negras, universitárias e ativistas dos feminismos branco e negro e movimento de mulheres.

Sem sombra de dúvida as negociações comandadas pelo PMDB Mulher por Escobar junto à Presidência da República imprimiram a este primeiro órgão de governo nacional um rosto feminista. Claro, que nestas negociações foram feitas concessões para atender ao leque partidário e foram nomeadas acadêmicas e ativistas feministas e do movimento de mulheres, sindicalista, escritoras e uma cineasta. A leitura da lista acima demonstra que na sua maioria as mulheres nomeadas tinham compromissos com estas demandas. ${ }^{5}$

No dia 10 de setembro de 1985 foi instalado em Brasília, nas dependências do Ministério da Justiça o CNDM, numa sessão presidida pela deputada Ruth Escobar e presentes as conselheiras indicadas pelo Presidente da República José Sarney. Na reunião, foram definidos os objetivos, metas e o programa geral de ação do CNDM. Ao final daquele mesmo mês foi publicado o Regimento Interno, Decreto No 96.895 de 30/09/1985. Seguramente, a existência do CNDM no espaço "oficial” da administração federal do Estado brasileiro foi uma ousadia para a velha política republicana nacional. Significava o entendimento de que se abria uma nova fase no espaço político nacional com as mulheres, estas timidamente emergiam neste cenário, reivindicando mais direitos e políticas públicas igualitárias para todas.

O CNDM iniciou sua gestão com um intenso corpo a corpo para desenvolver uma política feminista e para as mulheres no âmbito do Estado brasileiro. Foram aprovadas suas linhas de atuação e criada uma organização técnico-administrativa através de um corpo técnico que atuasse no dia a dia do CNDM. Esta estrutura mínima era composta por uma secretaria da presidência ocupada por Shuma Shumacher, uma diretoria técnica, cargo que foi ocupada por diferentes feministas acadêmicas e militantes: Maria Valéria Juno Pena, Ana Alice Alcântara, Vera Soares, Celina Albano, comissões técnicas sobre as áreas de trabalho, saúde, mulheres negras. Estiverem dirigindo estas atividades e desenhando políticas: Suely Carneiro, Edna Roland, Maria Luiza Heilbron, Comba Marques Porto entre outras. ${ }^{6}$

De uma maneira geral as reuniões com as conselheiras do CNDM aconteciam mensalmente e estas traçavam metas e linhas políticas de atuação. As propostas que o pleno do CNDM aprovava podiam ficar a cargo de uma das conselheiras, que se interessa-se pelo tema e esta junto com o corpo técnico e pesquisadoras convidadas desenvolviam uma proposta política de açãopara o Conselho. Assim, foram elaborados vários conteúdos relativos ao trabalho pago feminino e os menores rendimentos recebidos pelas mulheres, saúde da mulher, violência doméstica, racismo, creches. Ainda em 1985 foi elaborado um Programa de Trabalho, ofício No 102/85, da Presidente Ruth Escobar, dirigido às organizações do movimento de mulheres e feministas. Este programa sugeria a realização de seminários, palestras e debates nos diversos estados sobre a pauta feminista e das mulheres. O CNDM se propunha a reunir as reivindicações e os materiais que surgissem dos encontros para traçar uma ampla política pública para as mulheres.

Notem que a experiência do CNDM foi pioneira nos marcos do Estado brasileiro, que até então não dispunha de nenhuma política específica para as mulheres. Com exceção do Programa de Assistência Integral à Saúde da Mulher (PAISM) do Ministério da Saúde criado em 1984, como resultante da atuação nos anos anteriores do movimento feminista que havia construído um diálogo com o Ministério da Saúde, no rastro da luta pela descriminalização do aborto e destas conversas havia emergido esta política para a saúde feminina. A candidatura à reeleição de Escobar a deputada estadual pelo PMDB/SP exigia sua desincompatibilização 
da Presidência do CNDM no primeiro semestre de 1986 para concorrer a um novo mandato na Assembleia Legislativa do Estado de São Paulo. A socióloga e conselheira Jacqueline Pitanguy assumiu o mandato de Presidenta do CNDM até meados de 1989, quando, em oposição à tentativa do ministro da Justiça de tutelar o CNDM, todas as conselheiras demitiram-se dos seus cargos.

O fio norteador destas reminiscências é a atuação do CNDM no processo constituinte dos anos de 1985 a 1988. Seguramente estas ações foram, naqueles anos, as mais contundentes deste órgão. Visando o processo eleitoral que se aproximava, ainda em novembro de 1985, o CNDM lançou a Campanha Mulher e Constituintecom objetivo de escutar e construir as reivindicações femininas para o texto constitucional que iria substitui a Carta Federal de 1967 dos militares (Ver Figura 1).

FIGURA 1.

Campanha Mulher e Constituinte (impresso pelo CNDM para a luta parlamentar)

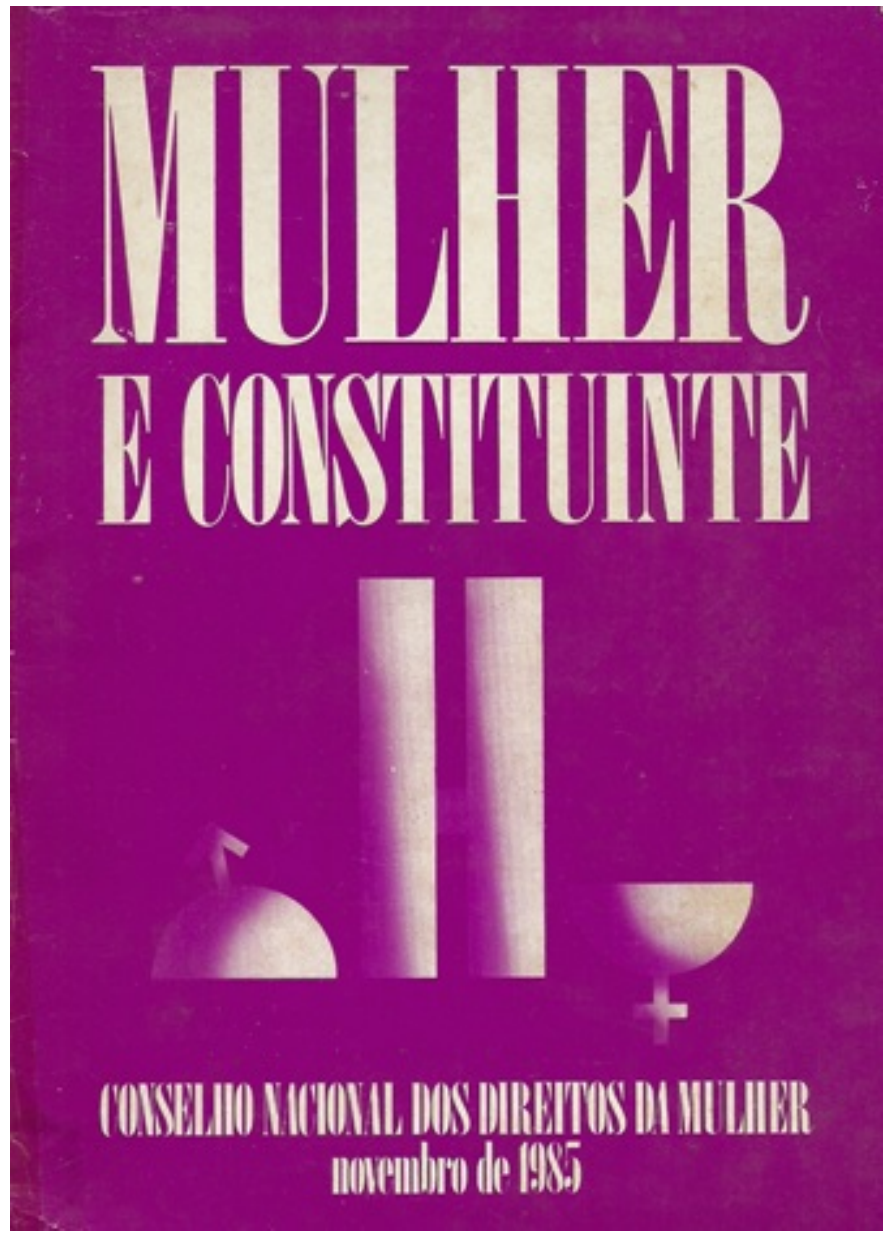

Fonte: documentação própria.

Convidou-se para coordenar esta campanha, em tempo integral a advogada carioca e ativista feminista Comba Marques Porto. Esta atividade foi a mais importante ação do CNDM naqueles anos em prol da igualdade das mulheres no Brasil. Claro que, nem todos os nossos sonhos foram contemplados na Carta Constitucional de 1988, mas atuação do CNDM junto ao Congresso Nacional foi pautada pelo compromisso de servir como canal de representação das mulheres brasileiras para as mudanças necessárias a plenitude de sua cidadania. Mas, é preciso registrar que de todas as Constituições nacionais -do Império as quatro anteriores da República- esta foi a primeira que escreveu com letra maiúscula os direitos das mulheres. Vejamos como este corpo a corpo foi feito pelo CNDM nos corredores do Congresso Nacional (ver Amâncio, 2013; Pitanguy, 1989; Thurler e Bandeira, 2010). 


\section{Constituinte Para Valer tem QUe ter PalaVra de MUlher!}

As ações junto aos parlamentares e comissões do Congresso Nacional foi a pauta mais significativa do CNDM nos trabalhos constituintes. O objetivo do Conselho foi que esta campanha atingisse todo o Brasil, e para isso o CNDM devia percorrer o território nacional empunhando a bandeira "Constituinte Para Valer Tem Que Ter Palavra De Mulher".

FIGURA 2.

Presidente da República do Brasil Sarney com a deputada Escobar na posse do CNDM em setembro de 1985 e Reunião do pleno do CNDM, ainda sob a presidência de Escobar.

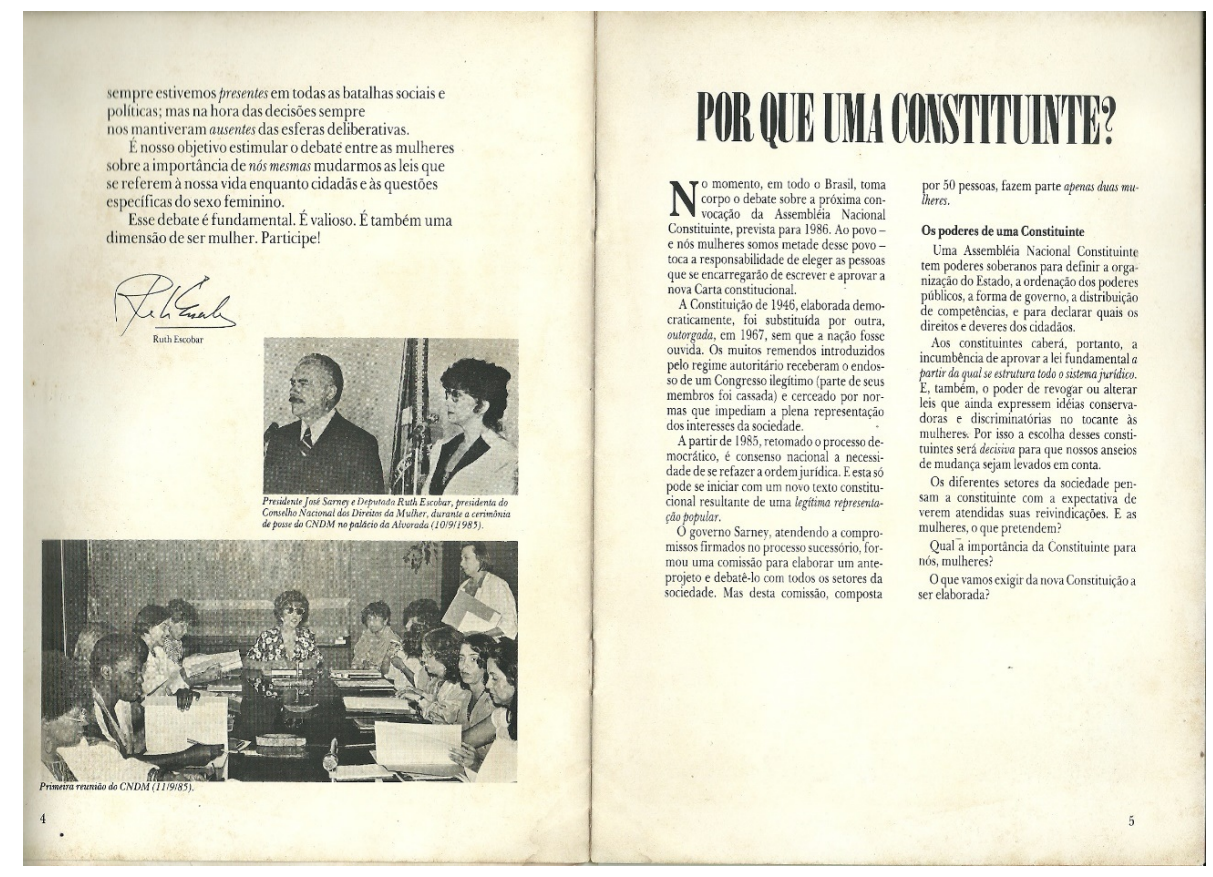

Fonte: documentação própria.

Todas as unidades da federação foram visitadas pela Coordenadora da Campanha e muitos dos encontros contaram com a presença de outras conselheiras do CNDM. Os atos constavam de um lançamento solene, com a presença de políticos e autoridades locais, do movimento de mulheres e feministas daquela unidade da federação. Além das discussões sobre as demandas das mulheres fazia-se uma convocatória para uma grande reunião em Brasília que deveria se realizar em meados de 1987 para aprovar o conjunto das propostas sonhadas e escritas pelas mulheres de todo o Brasil. O objetivo desta proposta era que este encontro de mulheres aprovasse a pauta de reivindicações que o CNDM levaria para o Congresso Nacional.

Tomava-se por princípio que o CNDM devia discutir com toda à nação as mudanças na lei que deviam tornar as mulheres sujeitas de suas vidas. Sugeria-se que os seminários e debates fossem realizados para unir forças para aprovar as emendas aprovadas no Encontro Nacional e que as mulheres acompanhassem os trabalhos constituintes, sobretudo através das representações parlamentares estaduais.

O documento aprovado no Encontro Nacional, no dia 26 de agosto de 1986, foi intitulado "Carta das Mulheres aos Constituintes”. Este encontro foi memorável porque reuniu mais de 200 mulheres, vindas de todas as unidades da Federação. Mulheres que se deslocaram para Brasília com recursos próprios e durante dois dias discutiram cada item das reivindicações levantadas na longa caminhada do CNDM pelo Brasil. Havia um conjunto expressivo de advogadas presentes ao Encontro que ajudaram na redação do texto final.O texto foi editado pelo CNDM e milhares de cópias foram distribuídas para as mulheres brasileiras, espalhadas pelo território nacional. Recomendava-se que estas propostas deveriam ser debatidas com a população em 
cada unidade da Federação e que as mulheres em seus estados pressionassem seus representantes no Congresso Nacional para votarem as propostas escritas na Carta das Mulheres aos Constituintes.

As negociações nos bastidores do Congresso Nacional foram duras ao longo destes meses, até a promulgação da Constituinte em 5 de outubro de 1988. O corpo técnico e de conselheiras construiu uma aliança tática com a Bancada Feminina que, naquela legislatura -1987/1991- havia sido ampliada para 29 parlamentares, enquanto na anterior -1983/1987- contávamos com apenasoito deputadas. 7 É preciso que fique claro que a partir da segunda metade dos anos 1970 houve um lento crescimento da representação política das mulheres no Congresso Nacional, seguramente refletindo a efervescência dos movimentos feministas pós 1975, embora a bancada feminina ainda nos dias atuais represente apenas cerca de 10,5\% da Câmara Federal (Pereira de Melo \& Thomé, 2018, gráfico 13, p. 135). Assim, pasme o leitor! As eleições de 1986 elegeu a mais numerosa bancada feminina da história política do Brasil até então. Provavelmente a multiplicação de mulheres na arena parlamentar refletia os novos tempos e o avanço das bandeiras de lutas desfraldadas com tanto afinco pelo movimento feminista pós-1975.

As mulheres eleitas naquele ano eram parlamentares de diferentes matizes ideológicos (umas mais à esquerda e outras menos), mas defenderam as propostas organizadas pelo CNDM e abriram muitas portas de comissões e subcomissão para nossa atuação. A bancada feminina teve a seguinte composição: Abigail Feitosa (PMDB/BA), Anna Maria Ratter (PMDB/RJ), Benedita da Silva (PT/RJ), Bete Mendes (PT/SP), Bete Azize (PSB/AM), Cristina Tavares (PMDB/PE), Dirce Tutu Quadros (PSC/SP), Eunice Michilles (PFL/ $\mathrm{AM})$, Eurides Brito (PP/DF), Irma Passoni (PT/SP). Lidice da Mata (PCdoB/BA), Lucia Braga (PFL/ $\mathrm{PB})$, Lucia Vânia Abrão Costa (PMDB/GO), Lurdinha Savignon (PT/ES), Márcia Cibilis Viana (PDT/ RJ), Márcia Kubitschek (PMDB/DF), Maria de Lourdes Abadia (PFL/DF), Maria Lucia Mello de Araujo (PMDB/AC), Maria Marluce Pinto (PTB/RR), Moema San Thiago (PDT/CE), Myrian Portella (PDS/ PI), MyrthesBevilacqua (PMDB/ES), Raquel Cândido (PDT/RO), Raquel Capiberive (PMDB/AM), Rita Camata (PMDB/ES), Rita Furtado (PDS/RO), Rose de Freitas (PMDB/ES), Sandra Cavalcanti (PFL/RJ), Wilma Maia (PDS/RN). Apesar da diversidade de partidos políticos, credos e convicçóes as parlamentares contribuíram significativamente para o sucesso da atuação do CNDM e do movimento social no processo constitucional. O leque partidário da bancada feminista expressava a própria composição do Congresso Nacional, com 34\% delas filiadas ao PMDB e as demais pulverizada pelos demais partidos, o PFL com quatro, e o PDT, PDS e o nascente PT com três deputadas cada um destes.

Destacamos o empenho de algumas deputadas com as propostas da "Carta das Mulheres aos Constituintes", a exemplo da incansável Benedita da Silva, da deputada convertida ao feminismo Ana Maria Rattes, da surpreendente Rita Camata, da médica Abigail Fonseca, da brava cearense Moema San Thiago, a irrequieta batalhadora feminista, a pernambucana Cristina Tavares, a baianinha lutadora feminista, Lídice da Mata e a representante do Amazonas, Eunice Michiles. ${ }^{8}$ Michiles, nos anos anteriores, tinha exercido mandato de senadora e via agora com mais simpatia a luta das mulheres. Os gabinetes das parlamentares estiveram abertos permanentemente às demandas feministas. Isso não significa que as demais não tenham colaborado, mas as deputadas mencionadas estão mais presentes nas minhas lembranças. Uma última observação sobre estas deputadas é que algumas delas ainda permanecem, nos dias atuais, com mandato no Congresso Nacional, como por exemplo, a senadora baiana Lídice da Mata, a deputada federal capixaba Rose de Freitas, a deputada federal fluminense Benedita da Silva. Com exceção de Rose de Freitas, Lídice e Benedita ainda nos dias atuais dedicam-se a causas feministas.

Outro aspecto fundamental do trabalho de persuasão parlamentar só foi possível porque contamos com um grupo aguerrido de advogadas feministas: destacamos as presenças de algumas magistradas que participaram ativamente destas ações. As juízas do Trabalho Dóris Louise Castro Neves e Maria Elizabete Junqueira Aires foram incansáveis assessoras no capítulo referente ao trabalho. Neves e Aires atuaram juntamente com as advogadas paulistas Silvia Pimentel, Floriza Verucci. Na tarefa árdua de redigir emendas e justificativas, destaco as cariocas Leila Linhares Barsted, Leonor Nunes Paiva, Branca Moreira Alves que, 
como assessoras da Coordenação Mulher e Constituinte sustentaram o trabalho de formiga do CNDM nas comissões parlamentares.

Deve-se também destacar a expressiva colaboração de alguns deputados tanto nas comissóes como no Plenário da Câmara Federal nos embates parlamentares. Foram defensores das demandas feministas os deputados José Paulo Bissol (PMDB/RS), Roberto Freire (PCB/BA), Marcelo Cordeiro (PMDB/BA) este último poderoso primeiro-secretário da Câmara Federal, Artur da Távola (PMDB/RJ).9 A Coordenação Mulher e Constituinte (CNDM) diariamente visitavam as comissões instaladas e tentava conversar com os deputados presentes sobre as reivindicações das mulheres. Sempre acompanhada pelas deputadas, corpo técnico e conselheiras do CNDM e os movimentos de mulheres e feministas. A sociedade civil tinha também uma forte mobilização que percorria diariamente os corredores do Congresso Nacional.

Havia uma questão crucial na nossa estratégia que era relativa à questão do aborto. A Igreja Católica tinha um abaixo-assinado com perto de 600 mil assinaturas pedindo a manutenção das restrições à interrupção da gravidez indesejada. Pelo movimento feminista também circulou um abaixo -assinado solicitando a sua liberação. O documento recebeu 24 mil assinaturas. Não havia paralelo, os católicos passavam o abaixoassinado durante as missas diárias e as feministas fizeram o que podiam para angariar assinaturas em suas relações de amizade e em manifestações nas cidades.

Na negociação encetada pelo CNDM com a bancada católica ficou explicito que, se insistíssemos na proposição de liberação do aborto, a bancada religiosa incluiria o direito à vida desde o ato da concepção. Tal inclusão significaria que o direito ao aborto nos casos de estupro e em risco de vida para a gestante desapareceria da legislação nacional e, conscientemente, recuamos da proposta de manter a descriminalização do aborto na pauta das negociações (Pereira de Melo, 2018).

Tudo não eram flores e a Subcomissão dos Direitos e Garantias Individuais (integrante da Comissão da Soberania dos Direitos Individuais do Homem e da Mulher) ofereceu resistência à pauta da igualdade e, sem a ajuda das argumentações dos parlamentares José Paulo Bissol (PMDB/RS) e Artur da Távola (PMDB/RJ), a pauta teria sido rejeitada. Bissol e Távola, parlamentares integrantes de comissões diferentes, negociaram com habilidade a inclusão da proposta da igualdade no texto final da CF 1988.

Outra ousadia e uma das maiores vitórias do lobby feminista foi assegurar no texto constitucional a igualdade na chefia conjugal. Em entrevista, Leonor Nunes Paiva relata os embates do deputado fluminense Artur da Távola na poderosa Subcomissão da Família com os colegas da bancada religiosa a respeito da "união estável" e que a negociação foi encerrada no acordo firmado na Subcomissão sobre a admissão da "união estável", mas que se manteria o efeito civil do casamento religioso. ${ }^{10}$

Outro ponto significativo que o CNDM negociou nos trabalhos constitucionais, refere-se ao parágrafo $8^{\circ}$ do artigo 226 da CF de 1988, cujo caput define a família como base da sociedade e destinatária da proteção do Estado. Sua introdução no texto da CF 1988 foi vital no convencimento de juristas e legisladores, em 2006, da constitucionalidade da Lei Maria da Penha, relativa ao crime de feminicídio. A coordenação da campanha do CNDM acompanhava 24 horas as negociações finais para a redação da Carta e,em um afogadilho, de madrugada, foi feita uma redação alternativa que garantisse que o Estado viesse a tratar a violência contra a mulher. Em entrevista, Comba afirmou que era importante que a palavra violência fosse escrita no texto constitucional para garantir essa proteção. Este pequeno detalhe foi a base constitucional para aprovação e sanção da Lei Maria da Penha (Lei no 11.340/2006). ${ }^{11}$

No campo do Trabalho a "Carta das Mulheres aos Constituintes" incluiu a reivindicação da extensão dos direitos trabalhistas e previdenciários as empregadas domésticas e as trabalhadoras rurais. A Subcomissão dos Direitos dos Trabalhadores e dos Servidores Públicos da Comissão da Ordem Social era bastante fechada nas negociações com a CNDM e movimentos feministas e de mulheres a incorporação das trabalhadoras domésticas no capítulo do trabalho. Ao repetir o passado patriarcal e escravocrata brasileiro, a Consolidação da Lei do Trabalho (CLT) de 1943 havia deixado fora da legislação laboral, tantos os trabalhadores rurais, como as empregadas domésticas. $\mathrm{Na}$ Carta de 1988, os trabalhadores rurais foram incluídos, mas as 
domésticas não tiveram todos os direitos reconhecidos. ${ }^{12}$ Só no século XXI, em abril de 2013 a legislação foi mudada e as empregadas domésticas ganharam todos os direitos trabalhistas e previdenciários. Em 1988, as trabalhadoras rurais venceram, mas as domésticas, não. Nosso lobby não deu conta do preconceito racial e do pesado patriarcalismo presente no Congresso Nacional e foi preciso esperar 25 anos para que esta reivindicação se tornasse lei em abril de 2013.

\section{CONCLUSÕES}

Recordar estes fragmentos da minha vivência feminista e conselheira do CNDM no período 1985/1989 permitiu refazer esta narrativa sobre a militância feminista e a atuação do CNDM no processo constituinte desses anos. Relembrar a atuação do CNDM do seu todo: funcionárias, direção e conselheiras da sociedade civil que com grande entusiasmo dedicaram tempo e horas de trabalho, para a construção de Carta Constitucional mais cidadãdo Brasil. Tais ações significaram colocar, a cada dia, um tijolo na construção da igualdade das mulheres no Brasil. Foi um trabalho do qual as mulheres que participaram deste corpo a corpo têm muito orgulho.

O significado de toda esta luta é dado pelo que está escrito na Carta Magna do Brasil de 1988 que "homens e mulheres são iguais em direitos e obrigações, nos termos desta Constituição" (Art. 5, I), que "os direitos e deveres referentes a sociedade conjugal são exercidos pelo homem e mulher" (Art. 226, 5\%). Um olhar para a história mostra a difícil caminhada que as mulheres empreenderam ao longo do tempo para escrever estas frases na Lei maior brasileira. Garantir a proteção dos direitos humanos das mulheres e a igualdade na sociedade conjugal foi, naquele momento, a maior conquista obtida pelo feminismo brasileiro.

No entanto, trinta anos depois ainda nos deparamos com lutas inconclusas como a violência contra as mulheres, a descriminalização do aborto, a renhida luta pela paridade salarial, a divisão das tarefas dos cuidados no interior das famílias. Além dessas importantes questões, há crimes que não se reduzem, como os recorrentes feminicídios, que ainda tem índices alarmantes no Brasil.No campo da política, em um olhar retrospectivo, podemos enfatizar que o CNDM foi um farol que impulsionoupelo Brasil afora a criação de conselhos estaduais e municipais. Estes com o objetivo de sugerir políticas públicas e ações para a cidadania feminina e trinta e dois anos depois sua chama não foi apagada. Apesar de todo o retrocesso que as políticas públicas de gênero e para as mulheres tiveram depois da cassação do mandato da Presidenta Dilma Vana Rousseff em abril de 2016. O CNDM originado numa lei federal não pôde ser simplesmente extinto. Vive na escuridão, como um fantasma na Esplanada dos Ministérios (Brasília). Os movimentos feministas e de mulheres esperam que o Conselho possa um dia renascer.

\section{REFERÊNCIAS}

Amâncio, K. C. B. (2013). Lobby do Batom: uma mobilização pelos direitos das mulheres. Trilhas da história, 3, 72-85.

Brasil. Congresso, Senado Federal (2012). Senadoras: dados biográficos: 1979-2012. Brasília, Senado Federal, Secretaria do Arquivo, Volume I - A-J.

Grupo Ceres (1981). Espelho de Vênus: identidade social e sexual da mulher. Rio de Janeiro: Brasiliense.

Novaes Marques, T. C. de (2016). A regulação do trabalho feminino em um sistema político masculino, Brasil: 1932-1943. Estudos históricos, 58, 667-686.

Pereira De Melo, H. e Novaes Marques, T. C. de (2000). Partido Republicano Feminino - a construção da cidadania feminina no Rio de Janeiro. Revista do Instituto Histórico e Geográfico do Rio de Janeiro, s/p, Disponível em https://cpdoc.fgv.br/sites/default/files/verbetes/primeira-republica/PARTIDO\%20REPUBLICANO\%2 OFEMININO.pdf 
Pereira de Melo, H. (2016). As sufragistas brasileiras: relegadas ao esquecimento? Revista do Instituto Histórico e Geográfico do Rio de Janeiro, 23(23).

Pereira de Melo, H. (2017). Reflexões e vivências sobre a militância feminista na segunda metade do século XX: Rio de Janeiro/Brasil (65 - 87 pp.). Em M. Tamanini, R. Boschila e S. F. Schwendler (orgs.), Teorias e políticas de gênero na contemporaneidade. Curitiba: Ed.UFPR.

Pereira De Melo, H., Soares, C. y Bandeira, L. M. (2017). A trajetória da construção da igualdade nas relações de gênero no Brasil: as empregadas domésticas (pp. 65-83). Em P. Bertolin, D. A. Andrade y M. S. Machado (orgs), Mulher, Sociedade e Vulnerabilidade, Erechin/RS, Editora Deviant.

Pereira de Melo, H. (2018). Histórias e memórias das lutas feministas no processo constitucional de 1985 a 1988: o papel do Conselho Nacional dos Direitos da Mulher (CNDM), (pp. 36 a 66). Em P. Tuma Martins Bertolin, D. A. de Andrade e M. Sapucaia Machado (orgs), Carta das Mulheres Brasileiras aos Constituintes - 30 anos depois. São Paulo: Editora Autonomia Literária.

Pereira de Melo, H. y Thomé, D. (2018). Mulheres e Poder, Histórias, Ideias, Indicadores. Rio de Janeiro: Editora da Fundação Getúlio Vargas.

Perrot, M. (2005). As mulheres ou os silêncios da história. Bauru: EDUSC.

Pimenta, F. F. (2010). Politicas feministas e os feminismos na politica. O Conselho Nacional dos Direitos da Mulher (1985-2005). Tese de Doutorado, Universidade de Brasília, Brasília.

Pitanguy, J. (2011). Mulheres, constituinte e constituição (pp. 17-45). Em Abreu, M. A. (org), Redistribuição, reconhecimento e representação - diálogos sobre igualdade de gênero. Brasília: IPEA.

Saffioti, H. I. B. (1976). A mulher na sociedade de classe: mito e realidade. Petrópolis: Vozes. Disponível em http://ww w.ipea.gov.br/portal/images/stories/PDFs/livros/livros/livro_redistreconhecimento.pdf

Teles de Almeida, M. A. (2017). Breve história do feminismo no Brasil e outros ensaios. São Paulo: Editora Alameda.

Thurler, A. L. y Bandeira, L. (2010). As mulheres e a constituição: ainda um processo em construção (pp. 34-69). Em Messenberg, D. [et al] (orgs.), Estudos legislativos: 20 anos da Constituição Brasileira, Brasília/DF: Senado Federal/Câmara Federal/Tribunal de Contas da União/UNB, vol.1.

\section{FonTES DOCUMENTAIS}

Brasil, Diário Oficial da União (DOU). Decreto No 91.227 de 6.5.1985, que institui a Comissão Especial incumbida de elaborar anteprojeto de lei que cria o Conselho Nacional de Defesa dos Direitos da Mulher

Brasil, Diário Oficial da União (DOU). Projeto de Lei No 5.778 de 1985 cria o Conselho Nacional do Direito da Mulher (CNDM) e nomeia suas conselheiras

Brasil, Diário Oficial da União (DOU), Decreto No 96.895 de 30.9.1985, que aprova o Regimento Interno do CNDM.

Brasil, Câmara Federal Site: https://www2.camara.leg.br/atividade-legislativa/legislação/Constituicao-cidada/consti tuintes/a-constituint-e-as-mulheres

Brasil, Ministério da Justiça, Arquivo Nacional do Rio de Janeiro, Seção de Instrumento de Pesquisa Provisório. Identificação: Fundo HP (Hildete Pereira), Dossiê Mulher, caixa 2.

BBC Brasil (2018) - site https://www.bbc.com/portuguese/geral-45245640.

\section{ENTREVISTAS}

Comba Marques Porto e Leonor Nunes Paiva, realizadas por Hildete Pereira de Melo em 14 de janeiro de 2018 e em agosto de 2008 . 


\section{Notas}

1. A lista com cinco mulheres foi a seguinte: a cientista Marie Curie (1867-1934) a maior delas segundo a pesquisa pelas suas pesquisas sobre a radiotividade e desenvolvimento do raio-X. Rosa Parks (1913-2005) símbolo da luta pelos direitos civis nos EUA nos anos 1950. Ada Lovelace (1815-1852) uma pioneira na computação, foi a primeira programadora do mundo junto com Charles Babbage. Rosalind Franklin (1920-1958) cientista pelas pesquisas na estrutura de dupla hélice do DNA.

2. Ver Pereira de Melo e Novaes Marques (2000).

3. Uma das mais significativas destas reuniões foi provavelmente à realizada em Belo Horizonte, em salas de aula da Universidade Federal de Minas Gerais, onde se virou a noite discutindo a conjuntura política, os rumos do movimento feminista e sua participação nas políticas públicas diante do novo quadro político que se esboçava no país.

4. Ver sobre a criação do CNDM a tese de doutorado (UnB) de Fabrícia Faleiros Pimenta (2010).

5. Como fui também conselheira efetiva do CNDM de 1985 a 1989, estas notas correspondem àslembranças que guardo daqueles tempos.

6. Estes nomes brotam de minha memória sobre este tempo, estes foram marcados por um forte ativismo do CNDM nos anos 1986 a 1989. Estas mulheres eram técnicas e também ativistas feministas e coordenavam "Comissões Técnicas do CNDM". As possíveis lacunas devem ser explicadas pela ausência de documentação sobre estes anos.

7. As legislaturas iniciam-se desde aqueles anos em 01 de fevereiro de cada ano. Por isso, o último ano refere-se apenas a 30 dias úteis (janeiro).

8. Eunice Michiles (1929 - ) deputada do PFL amazonense havia exercido o mandato de senadora de maio de 1979 a janeiro de 1987 sendo eleita deputada federal para a legislatura de 1987 - 1991. Suplente do senador João Bosco (AM), assumiu o mandato devido a sua morte. Foi a primeira mulher no Senado Federal (ver Brasil. Senado Federal, 2012).

9. Entrevista da juíza do trabalho aposentada Comba Marques Porto a Hildete Pereira de Melo, no dia 14 de janeiro de 2018.

10. Entrevista da Procuradora do Estado do Rio de Janeiro Leonor Nunes Paiva a Hildete Pereira de Melo, em 14 de janeiro de 2018.

11. Nunca esquecer que foram as organizações feministas que, junto à sucessora do CNDM a Secretária de Políticas para as Mulheres da Presidência da República (2003/2017), na gestão da Ministra Nilcea Freire, ao lado da deputada Jandira Feghali (PCdoB/RJ), relatora do projeto de Lei, coordenaram no primeiro governo Lula a importante batalha do combate à violência contra as mulheres.

12. Sobre este tema ver Pereira de Melo, Soares y Bandeira (2017, pp. 65-83). 